\title{
A PROTEÇÃO JURÍDICA DOS “REFUGIADOS AMBIENTAIS" NAS TRÊS VERTENTES DA PROTEÇÃO INTERNACIONAL DA PESSOA HUMANA
}

\author{
International Protection of the Human Person and new forced \\ displacements: protection challenges for \\ "environmental refugees"
}

Carolina de Abreu Batista Claro*

\begin{abstract}
Resumo. As três vertentes da proteção internacional da pessoa humana, compostas pelo Direito Internacional dos Direitos Humanos, Direito Internacional Humanitário e Direito Internacional das Pessoas Refugiadas (também conhecido como Direito Internacional dos Refugiados), não possuem normativa jurídica específica para proteger os "refugiados ambientais". Não obstante, esses três regimes internacionais podem ser aplicados às pessoas migrantes induzidas por causas ambientais caso elas se encontrem em situações previstas por esses conjuntos normativos. Por meio de pesquisa bibliográfica e documental, o presente artigo analisa as formas pelas quais essas três áreas do direito internacional contribuem para proteger e reconhecer os direitos dos "refugiados ambientais".
\end{abstract}

Palavras-chave: Migração; Direitos Humanos; Direito Internacional Humanitário; Direito Internacional das Pessoas Refugiadas; "Refugiados Ambientais".

Abstract. The three pathways for the international protection of the human person, consisting of International Human Rights Law, International Humanitarian Law and International Refugee Law, do not have specific rules to protect "environmental refugees". However, these three international regimes can be applied to environment-induced migrants if they find themselves in situations recognized by these sets of rules. Using bibliographical and documental research methods, this article examines the ways in which these three areas of international law contribute to protect and recognize the rights of "environmental refugees".

Keywords: Migration; Human Rights; International Humanitarian Law; International Refugee Law; "Environmental Refugees".

Bolsista PNPD/CAPES e professora voluntária no Instituto de Relações Internacionais da UnB. Brasília - DF, Brasil. E-mail: cclaro@gmail.com. Orcid: 0000-0002-9443-2044. 


\section{Introdução ${ }^{1}$}

A crescente intensidade dos eventos naturais extremos, combinada com a percepção de aumento no número de desastres pelo mundo, tem motivado movimentos migratórios e, de forma ainda tênue, tem contribuído para as buscas de soluções jurídicas e políticas sobre como caracterizar e respaldar jurídica e socialmente as pessoas migrantes motivadas por causas ambientais.

Primeiramente, cabe considerar a dificuldade de identificar todas as situações em que o fator ambiental se faz presente na decisão de migrar: diante de um desastre de início rápido, como no caso de terremotos, maremotos e enchentes, fica nítida a relação entre a mobilidade humana no espaço geográfico e o evento ambiental que desencadeou o movimento migratório; nas situações, porém, em que a causa ambiental é remota (como na desertificação, poluição e escassez de recursos naturais), a relação de causalidade pode ficar menos evidente, já que a pessoa migrante poderá alegar outros fatores (econômicos, laborais, familiares) que impulsionaram a migração.

Em segundo lugar, ressalta-se não apenas a dificuldade de discussão do tema nos fora internacionais, como também a falta de consenso sobre uma nomenclatura apropriada para se referir a esses migrantes. Os termos encontrados na literatura especializada, entre os quais também se encontram aqueles defendidos por diferentes tomadores de decisão, variam entre "migrante ambiental", "migrante ambientalmente forçado", "deslocado ambiental", "migrante climático" e "eco migrante".

Usualmente, o termo "refugiado ambiental" não é aceito entre defensores do Direito Internacional das Pessoas Refugiadas ${ }^{2}$ stricto sensu, embora a Convenção de 1951 sobre o Estatuto dos Refugiados refira-se explicitamente que seu texto será aplicado apenas para as pessoas caracterizadas no seu artigo 2(1)(A), não havendo exclusividade do uso do termo "refúgio" com relação a outros documentos internacionais.

Não obstante, o presente artigo utilizará "refugiado ambiental" para referir-se "[...] àquelas pessoas que foram forçadas a deixar seu habitat tradicional, temporária ou permanentemente, em razão de uma ruptura ambiental (natural e/ou ocasionada pelo homem) que ameaçou sua existência e/ou seriamente afetou sua qualidade de vida" (El-Hinnawi, 1985, p. 4). Entende-se, ainda, que se tratam de migrantes forçados (Betts, 2009a), já

1 O presente trabalho foi realizado com apoio da Coordenação de Aperfeiçoamento de Pessoal de Nível Superior (CAPES). Código de Financiamento 001.

2 O artigo utilizará a expressão "Direito Internacional das Pessoas Refugiadas" ao invés de "Direito Internacional dos Refugiados", uma vez que existe um movimento crescente por parte de atores da sociedade civil (incluída a academia) e do próprio ACNUR para modificar a nomenclatura da disciplina com base em considerações de gênero. 
que buscam abrigo frente a uma situação de perigo por sua sobrevivência ou integridade física.

Nas palavras de Gemenne, Brücher e lonesco, "sejam eles [os "refugiados ambientais"] chamados de migrantes ou refugiados, afetados por desastres causados pela interferência antrópica ou por eventos naturais, todos esses que migram ou são deslocados buscam proteção, formas de sobrevivência e oportunidades para um futuro mais seguro" $(2012$, p. 7).

Assim como não existe consenso absoluto sobre a nomenclatura utilizada, tampouco é possível conhecer com precisão a quantidade de "refugiados ambientais" no mundo, seja por falta de dados específicos ou mesmo pelo não reconhecimento dessa categoria migratória. Estimativas apontam grande diversidade e incertezas referentes aos números de pessoas forçadas a migrar interna ou internacionalmente por motivos ambientais, variando entre dezenas de milhares que já se encontram nessas condições até aproximadamente 2 bilhões de "refugiados ambientais" até 2100 em todo planeta (Geisler, Currens, 2017; EJF, 2017).

Considerando os tabus que ainda cercam o tema (da descrença de que o movimento migratório é internacional e não apenas interno, perpassando pelas dificuldades terminológicas, políticas e jurídicas internacionais), e diante da inexistência de normas globais e vinculantes específicas sobre a proteção jurídica dos "refugiados ambientais", o presente artigo buscará identificar, na literatura especializada e nos acordos internacionais, a possibilidade de respaldá-los juridicamente dentro dos sistemas protetivos existentes da proteção internacional da pessoa humana, de modo a utilizar os mecanismos presentes no direito internacional.

\section{A atual proteção jurídica dos "refugiados ambientais" nas três vertentes da proteção internacional da pessoa humana}

As três vertentes da proteção internacional da pessoa humana, compostas pelo Direito Internacional dos Direitos Humanos (DIDH), Direito Internacional Humanitário (DIH) e Direito Internacional das Pessoas Refugiadas (DIR) têm como principal convergência a proteção dos direitos da pessoa humana (Cançado Trindade, 1996), seja sob uma perspectiva abrangente (DIDH) ou específica (DIH e DIR).

Enquanto o DIDH trata da proteção de toda pessoa indiscriminadamente e a qualquer momento, o DIH dispõe de normas a serem observadas durante conflitos armados internos ou internacionais e o DIR protege, em tempos de paz ou guerra, quem possui fundado temor de perseguição por motivos de raça, religião, nacionalidade, pertencimento a grupo social ou opiniões políticas e está em situação de migração forçada internacional. 


\subsection{Os "refugiados ambientais" no Direito Internacional dos Direitos Humanos}

A afirmação histórica dos direitos humanos ocorrida especialmente a partir da Declaração Universal dos Direitos Humanos (DUDH), de 1948, que marca o "aprofundamento e internacionalização desses direitos" (Comparato, 2019, p. 57), permitiu a sistematização da normativa internacional de direitos humanos tanto na forma de instrumentos jurídicos de proteção aplicável a todos os indivíduos ${ }^{3}$ quanto de instrumentos específicos aplicáveis a grupos vulneráveis ${ }^{4}$. Para fins didáticos, costuma-se, ainda, dividir os tratados de direitos humanos entre os de alcance global e os de alcance regional ${ }^{5}$.

Assim como nas demais áreas do direito, o DIH, DIDH e DIR surgem do costume, das leis, dos princípios de direito, da literatura jurídica e da jurisprudência. Por isso, o artigo 38 do Estatuto da Corte Internacional de Justiça indica como fontes primárias do direito internacional os tratados, o costume internacional e os princípios gerais de direito; suas fontes secundárias, por sua vez, são a literatura jurídica especializada e a jurisprudência.

De acordo com Carvalho Ramos (2019), deve-se considerar que os direitos humanos possuem duas categorias de fontes: uma legislativa e uma jurisprudencial, o que significa que não apenas serão importantes as normas jurídicas na construção do arcabouço jurídico de direitos humanos, mas, sobretudo, a interpretação conferida pela prática judicial dos Estados e dos tribunais internacionais a esse respeito.

No que tange ao objeto central deste artigo, o DIDH confere proteção aos "refugiados ambientais" de forma genérica, sem menção específica ao tema. Pode-se considerar que a DUDH os protege em todos os seus artigos, especialmente nos artigos 13 e 14 a respeito do direito de migração, emigração e de buscar asilo.

Segundo os artigos 13(1) e 13(2) da DUDH, "toda pessoa tem direito à liberdade de locomoção e residência dentro das fronteiras de cada Estado" e "toda pessoa tem o direito de deixar qualquer país, inclusive o próprio, e a este

3 Entre eles, podem-se citar: Declaração Universal de Direitos Humanos (1948), Pacto Internacional de Direitos Civis e Políticos (1966), Pacto Internacional de Direitos Econômicos, Sociais e Culturais (1966), Convenção sobre a Prevenção e Repressão do Crime de Genocídio (1948), Convenção para a Eliminação de todas as Formas de Discriminação Racial (1965), Convenção contra a Tortura e outros Tratamentos ou Penas Cruéis, Desumanas ou Degradantes (1984).

4 A exemplo de: Convenção para a Eliminação de todas as Formas de Discriminação contra a Mulher (1979), Convenção relativa aos Direitos da Criança (1989), Convenção sobre o Estatuto dos Apátridas (1954), Convenção para a Prevenção e Redução dos Casos de Apatridia (1961), Convenção Internacional para a Proteção dos Direitos dos Trabalhadores Migrantes e Membros de suas Famílias (1990).

5 Deles fariam parte os tratados internacionais dos sistemas regionais de direitos humanos, como aqueles do sistema europeu, interamericano e africano. 
regressar". E "toda pessoa, vítima de perseguição, tem o direito de procurar e de gozar asilo em outros países" (art. 14, 1), com a salvaguarda de que "este direito não pode ser invocado em caso de perseguição legitimamente motivada por crimes de direito comum ou por atos contrários aos propósitos e princípios das Nações Unidas" (art. 14, 2).

Igualmente, o Pacto Internacional de Direitos Civis e Políticos (1966) afirma, em seus artigos 12(1) e 12(2), que "todo o indivíduo legalmente no território de um Estado tem o direito de circular livremente e de aí escolher livremente a sua residência" e que "todas as pessoas são livres de deixar qualquer país, incluindo o seu".

Embora a DUDH e o Pacto Internacional de Direitos Civis e Políticos observem a importância de se respeitar o direito de uma pessoa migrar do seu país de origem ou mesmo dentro dele, o tema migratório encontra resistências de normatização no plano internacional que ultrapasse os princípios neles indicados. A Convenção da ONU sobre os Direitos de Todos Trabalhadores Migrantes e Membros de suas Famílias (1990) conta com apenas 55 Estados-parte $^{6}$, dos quais nenhum é considerado país de imigração ou economicamente desenvolvido.

De acordo com Battistella,

[A Convenção sobre os Trabalhadores Migrantes (1990)] é o maior dos instrumentos da ONU, teve o processo mais lento entre a adoção e a entrada em vigor e tem o menor número de Estados participantes. Isso não é coincidência, mas está intrinsicamente ligado à dificuldade da comunidade internacional em aproximar a migração da perspectiva de direitos humanos e concordar em padrões para sua gestão; (2009, p. 47 - tradução livre)

A dificuldade de se efetivar uma normatização coesa em matéria de migrações deve-se em parte à resistência dos países em adotarem normas jurídicas e políticas de respeito aos direitos humanos e não baseadas primordialmente na soberania, na segurança e nos interesses nacionais como hoje amplamente ocorre (Mármora, 2010). Por isso, Dauvergne afirma que "as leis sobre migração têm-se tornado o último bastião da soberania, a questão chave para se contestar o núcleo tanto de 'nação' quanto de 'estado'" (Dauvergne, 2008, p. 2).

Aos "refugiados ambientais" cabem as disposições dos tratados internacionais sobre o direito de migrar e também relativas a todos os demais direitos humanos, gerais ou específicos, encontrados tanto nos tratados internacionais de alcance global quanto nos de alcance regional, assim como nos costumes internacionais e nas demais formas de expressão do direito internacional. A justificativa de proteção dos "refugiados ambientais" no DIDH

${ }_{6}$ Disponível em: <https://treaties.un.org/>. Acesso em: 06.04.2020. 
deve-se em razão da sua condição de seres humanos dotados de personalidade jurídica e protegidos, por isso, pelo arcabouço normativo e institucional do $\mathrm{DIDH}$.

Se os enunciados da DUDH e do Pacto Internacional de Direitos Civis e Políticos encontram resistência na sua efetivação, seja por meio de políticas migratórias restritivas e em desrespeito aos direitos humanos das pessoas migrantes ou pela dificuldade de serem consagrados em um amplo tratado sobre o tema - como na Convenção da ONU sobre os Direitos de Todos Trabalhadores Migrantes e Membros de suas Famílias, maiores dificuldades devem ser esperadas não apenas na normatização de uma proteção jurídica internacional para os "refugiados ambientais", mas, principalmente, no seu respeito e na sua eficácia.

Em matéria de questões ambientais que interferem nos direitos humanos, deve-se considerar que as mudanças climáticas são apenas um dos aspectos ambientais capazes de interferir no exercício desses direitos ${ }^{7}$. Elas podem infringir diretamente o direito à vida, à saúde, à habitação, à alimentação, à água, entre outros direitos humanos amplamente consagrados no plano internacional (Mclnerney-Lankford, Darrow, Rajamani, 2011) e em instrumentos como a DUDH e o Pacto Internacional de Direitos Civis e Políticos (1966).

Ademais, as situações de emergência tendem a limitar a aplicação das normas de direitos humanos, ou por força de lei (em que a derrogação é prevista) (Humphreys, 2010) ou por ineficácia das políticas públicas (McLnerney-Lankford, Darrow, Rajamani, 2011). Embora as normas de direitos humanos sejam de aplicabilidade imediata, o recurso aos tribunais domésticos e internacionais é frequente para efetivar acesso a direitos garantidos na normativa interna e internacional.

Em sede do mecanismo de tratados do Comitê de Direitos Humanos da ONU, mais especificamente no Comitê de Direitos Civis e Políticos (CCPR, na sigla em inglês), houve importante reconhecimento de que as mudanças climáticas impactam diretamente os direitos humanos, sobretudo o direito à vida, o que serviu de argumento para que um nacional de Kiribati recorresse ao CCPR ao ter sua condição migratória de "refugiado ambiental" negada na Nova Zelândia (UNHRC/CCPR, 2020).

\footnotetext{
Podem-se pensar, por exemplo, nos fenômenos ambientais que independem da mudança do clima e mesmo assim são capazes de interferir no exercício dos direitos humanos, como vulcões e terremotos. As queimadas e os deslizamentos de terra também são exemplos de rupturas ambientais, causados ou não pela interferência antrópica no meio ambiente, que podem afetar o exercício dos direitos humanos.
} 


\subsection{Os "refugiados ambientais" no Direito Internacional Humanitário}

O Direito Internacional Humanitário, também conhecido como direito da guerra ou direito dos conflitos armados, é composto pelos chamados "Direito da Haia", "Direito de Genebra", "Direito de Nova lorque" e o "Direito de Roma", conforme a origem das suas normas ${ }^{8}$. De acordo com Sassòli e Bouvier, "o direito internacional humanitário pode ser definido como um ramo do direito internacional que limita o uso da violência durante os conflitos armados [...]" (2003, p. 83) e é baseado (i) na distinção entre civis e combatentes, (ii) na proibição de atacar pessoas fora do combate, (iii) na proibição de infligir sofrimentos desnecessários e mal supérfluo, (iv) no princípio da necessidade e (v) no princípio da proporcionalidade.

Embora o DIH não trate especificamente dos "refugiados ambientais", são aplicáveis a eles todas as normas de DIH caso a pessoa migrante se encontre em situação de conflito armado interno ou internacional. Ademais, ao longo da sua evolução histórica recente, o DIH passou a tratar da proteção de pessoas em situações de desastres e prestar assistência às pessoas migrantes em situações além da perspectiva de conflito, incluindo os esforços em reunir famílias separadas e encontrar migrantes desaparecidos. No tema das migrações forçadas, o DIH conta com "resposta humanitária para proteção das necessidades dos solicitantes de refúgio, refugiados, deslocados internos e migrantes vulneráveis" (Moretti, Bonzon, 2017, p. 154).

Em razão do grande número de vítimas de desastres ambientais, os órgãos que aplicam e promovem o $\mathrm{DIH}^{9}$, sobretudo o Comitê Internacional da Cruz Vermelha (CICV), a Federação Nacional da Cruz Vermelha e do Crescente Vermelho (IFRC, na sigla em inglês), bem como as sociedades nacionais da Cruz Vermelha e do Crescente Vermelho, têm prestado assistência humanitária

8 Diz-se "Direito da Haia" à gênese dos tratados internacionais de DIH, notadamente às Convenções da Paz da Haia de 1899 e 1907. O "Direito de Genebra" originou-se com Henry Dunant, com a Convenção de 1864 para prestar assistência aos feridos e combatentes de guerra, as duas Convenções de Genebra de 1929 para a proteção dos feridos em guerra e sobre a proteção dos prisioneiros de guerra, além daqueles que são considerados os pilares do DIH: as quatro Convenções de Genebra de 1949, seguidas por dois protocolos adicionais em 1977. As Convenções de Genebra de 1949 referem-se a: (i) Convenção para Melhorar a Situação dos Feridos e Doentes das Forças Armadas em Campanha; (ii) Convenção para Melhorar a Situação dos Feridos, Doentes e Náufragos das Forças Armadas no Mar; (iii) Convenção Relativa ao Tratamento dos Prisioneiros de Guerra; e (iv) Convenção Relativa à Proteção das Pessoas Civis em Tempo de Guerra. O "Direito de Nova lorque", por sua vez, refere-se aos esforços da ONU em promover o DIH e no estabelecimento dos tribunais internacionais ad hoc pela Organização. Já o "Direito de Roma" diz respeito à criação do Tribunal Penal Internacional pelo Tratado de Roma (1998), que estabelece bases para a persecução penal individual em face de violações de DIH (Borges, 2006).

9 São órgãos de promoção e aplicação do DIH: o Comitê Internacional da Cruz Vermelha (CICV), a Federação Internacional da Cruz Vermelha e do Crescente Vermelho e as Sociedades Nacionais da Cruz Vermelha e do Crescente Vermelho (Fernandes, 2006). 
às pessoas por ocasião desses desastres, mesmo que eles não envolvam conflitos $\operatorname{armados}^{10}$, uma vez que o DIH é aplicável não apenas em tempos de guerra, mas igualmente em períodos de paz (Fernandes, 2006).

Como forma de ampliar a atuação dos órgãos de DIH no tema migratório, a Federação Internacional da Cruz Vermelha e do Crescente Vermelho (IFRC, na sua sigla em inglês) publicou um Guia Educacional sobre Princípios relacionados à Migração (IFRC, s/d), entre os quais constam:

i) Enfoque nas necessidades e vulnerabilidades das pessoas;

ii) Inclusão de migrantes nos programas humanitários;

iii) Apoio às aspirações dos migrantes;

iv) Reconhecimento dos direitos dos migrantes;

v) Relacionar assistência, proteção e defesa humanitária para migrantes;

vi) Construir parcerias para os migrantes;

vii) Trabalhar nas rotas migratórias;

viii) Assistência no retorno de migrantes;

ix) Responder ao deslocamento de pessoas; e

x) Diminuir as pressões migratórias nas comunidades de origem.

Da mesma forma que dificilmente se terá precisão no número de "refugiados ambientais" pelo mundo, em razão da multiplicidade de fatores que podem impulsionar os movimentos migratórios, tampouco é totalmente possível isolar os conflitos armados com causas unicamente ambientais. O que já se evidencia é que a escassez de recursos naturais pode efetivamente contribuir para amplificar tensões sociais, econômicas e políticas, somando-se às demais causas dos conflitos (Homer-Dixon, 1994).

Não obstante, se as previsões de aumento dos conflitos incentivados pelas mudanças climáticas se tornarem verdadeiras ${ }^{11}$, a demanda pela aplicabilidade das normas de DIH igualmente se fará presente ${ }^{12}$ seja na sua forma "clássica" relativa aos conflitos armados internos ou internacionais ou mesmo na perspectiva da proteção de pessoas em situação de desastres ambientais.

${ }_{10}$ A assistência humanitária no DIH é baseada no artigo 23 caput da IV Convenção de Genebra de 1949, segundo o qual os agentes humanitários promoverão a entrega de medicamentos, de material sanitário e de objetos necessários ao culto, bem como objetos de vestuário e víveres indispensáveis à população afetada.

11 Segundo Smith e Vivekananda, "[...] Há 46 países - que abrigam 2.7 bilhões de pessoas - nos quais a interação entre os efeitos da mudança do clima com problemas econômicos, sociais e políticos irá criar um alto risco de conflito violento" (Smith, Vivekananda, 2007).

12 De acordo com Welzer, "[...] A violência sempre foi uma opção nos relacionamentos humanos e é inevitável que soluções violentas também sejam encontradas para os problemas futuros, quando retornarem condições ambientais desfavoravelmente modificadas" (grifos no original) (Welzer, 2010, p. 16). 
Ademais, por um lado se nota que há maior probabilidade de que as causas ambientais de início lento e de início rápido contribuam diretamente como fatores push e pull para migrantes econômicos ou migrantes forçados por motivos associados ao meio ambiente (Hugo, 1996; Bardsley, Hugo, 2010). Por outro lado, pessoas em situação de refúgio convencional não teriam, em princípio, fatores ambientais de início lento como incentivadores do movimento migratório (Homer-Dixon, 1994).

\subsection{Os "refugiados ambientais" no Direito Internacional das Pessoas Refugiadas}

A gênese do DIR remonta às mais variadas formas de perseguição de grupos humanos, individual ou coletivamente, que se tornaram uma séria preocupação da comunidade internacional no século XX e que, graças aos esforços empreendidos no âmbito da Liga das Nações, culminaram no desenvolvimento da normativa internacional sobre o tema (Fischel De Andrade, 1996), cujo ápice é representado pela Convenção de 1951 sobre o Estatuto dos Refugiados (a partir daqui, "Convenção de 51"), alterada pelo Protocolo Relativo ao Estatuto dos Refugiados, de 1967.

Embora o DIR não contemple os desastres ou quaisquer causas ambientais como categoria sob a qual uma pessoa pode solicitar refúgio, o "refugiado ambiental" poderá ser um refugiado convencional caso se encontre nas situações descritas no artigo 1(A) da Convenção de $51^{13}$. Se assim for, ele será considerado, para todos os efeitos, um refugiado convencional e não um "refugiado ambiental" mesmo que um fator ambiental tenha dado causa ao fundado temor de perseguição descrito na Convenção.

Um dos principais argumentos sob os quais se critica uma eventual modificação na Convenção de 51 para a inclusão dos desastres ou causas ambientais como possíveis situações que qualificariam o refúgio é o fato de que neles não se encontra claramente o fundado temor de perseguição (McAdam, 2010), uma vez que o agente perseguidor (meio ambiente) não poderia ser claramente qualificado ou definido em uma solicitação de refúgio.

A respeito do tema e vislumbrando situação em que o agente perseguidor utiliza o meio ambiente como forma de perseguição, Jubilut e Apolinário ponderam:

\footnotetext{
${ }^{13}$ Segundo o qual será refugiado qualquer pessoa que "temendo ser perseguida por motivos de raça, religião, nacionalidade, grupo social ou opiniões políticas, encontra-se fora do país de sua nacionalidade e que não pode ou, em virtude desse temor, não quer valer-se da proteção desse país, ou que, se não tem nacionalidade encontra-se fora do país no qual tinha sua residência habitual em consequência de tais acontecimentos, não pode ou, devido ao referido temor, não quer voltar a ele".
} 
Diferentemente das vítimas de perseguição, as pessoas que se deslocam em razão de um desastre ambiental podem, em geral, valer-se da ajuda e do suporte do próprio governo, mesmo que tal suporte seja limitado. Isso não se confunde com a situação em que o agente perseguidor utiliza a degradação ambiental como meio de perseguição. Neste caso, a razão da perseguição pode ser uma das previstas na Convenção de 1951, e a forma de perseguição é o dano ambiental; assim, trata-se de um refugiado. Nesse sentido, deve-se estabelecer o fundado temor de perseguição. (2010, p. 288)

Não obstante o "refugiado ambiental" não ser, per se, um refugiado e apesar de existir muita controvérsia sobre esta nomenclatura, é importante considerar que mesmo os organismos internacionais responsáveis pela assistência aos refugiados e pela promoção do DIR têm reconhecido o aumento das migrações forçadas relacionadas ao meio ambiente e têm agido em nome da solidariedade internacional ${ }^{14}$ para prestar assistência a essas vítimas ${ }^{15}$, mesmo que os refugiados não convencionais não estejam sob seu mandato (Maertens, 2012).

No caso dos "refugiados ambientais", a judicialização ainda é tímida e geralmente voltada para o reconhecimento da condição migratória específica de pessoas em situação de migração forçada por motivos ambientais.

A título de exemplo, o Tribunal de Apelação de Sidney, na Austrália, manteve decisão administrativa de negar refúgio a uma família de Kiribati em razão da diminuição da qualidade de vida no seu país de origem decorrente do aumento do nível do mar, o que tem ocasionado diminuição do espaço territorial e salinização da água, somando ao aumento da pobreza e da dificuldade de autossubsistência ${ }^{16}$. Em decisão similar, a Suprema Corte da Nova Zelândia reforçou o entendimento de que não cabe o reconhecimento do refúgio convencional para outra família proveniente de Kiribati, que alegava "perseguição" motivada pelas mudanças climáticas ${ }^{17}$.

${ }^{14}$ Em discurso proferido em maio de 1998, o então Alto Comissário da ONU para Refugiados, Sadako Ogata, afirmou que "solidariedade não é apenas um valor moral", lembrando Fridtjof Nansen de que "caridade é realpolitik". Para Nansen, a ajuda humanitária era uma prioridade, haja vista que "[...] a comunidade internacional não podia ignorar as crises humanitárias [pós I Guerra Mundial] não apenas por razões morais, mas também porque elas colocavam em risco a paz mundial". Disponível em: <https://blogs.icrc.org/cross-files/fridtjof-nansen/\#_ftn15>. Acesso em: 06.04.2020.

${ }^{15}$ Como exemplo, vide discurso de José Rivera, alto funcionário do ACNUR, por ocasião de conferência ocorrida em janeiro de 2013 na Alemanha. Disponível em: <http://www.unhcr. org/5151bf239.html>. Acesso em: 06.04.2020.

16 AUSTRALIA. SYDNEY APPELATION TRIBUNAL. 0907346 [2009] RRTA 1168, 10 December 2009. Disponível em: <https://www.refworld.org/pdfid/4b8fdd952.pdf>. Acesso em: 06.04.2020.

17 NEW ZEALAND. SUPREME COURT OF NEW ZEALAND. Ioane Teitiota v. The Chief Executive of the Ministry of Business, Innovation and Employment. [2015] NZSC 107, 20 July 2015. Disponível em: <https://www.refworld.org/cases,NZL_SC,55c8675d4.html>. Acesso em: 06.04.2020. 
A decisão do CCPR, de novembro de 2019, ocorreu em sede de procedimento individual quasi judicial do sistema ONU. Ela inovou não apenas no sentido de reconhecer o impacto das mudanças climáticas em toda gama de direitos humanos, mas também em afirmar que os Estados não devem devolver imigrantes para países onde sua vida possa estar em perigo, mesmo em se tratando de condições ruins de vida ocasionadas por fatores ambientais (UNHRC CCPR, 2019). Ainda que a decisão não seja vinculante e seja aplicável apenas naquele caso concreto, vale destacar que ela constitui um precedente importante na aplicabilidade do princípio da não devolução (ou non-refoulement) para os "refugiados ambientais".

O princípio da não devolução é um dos princípios norteadores do DIR, segundo o qual a pessoa refugiada ou solicitante de refúgio não pode ser devolvida compulsoriamente para o país de origem ou para terceiro país onde sua vida ou integridade física possam estar em perigo ${ }^{18}$. Ele é considerado tão importante e basilar para o DIR que é também reconhecido como princípio de direito internacional (Crépeau, 2017) e costume internacional (Coleman, 2003).

No que tange às formas de proteção jurídica destinadas aos "refugiados ambientais", é importante considerar as normas, princípios e costumes já existentes nas três vertentes da proteção internacional da pessoa humana, de modo a garantir o exercício de direitos gerais e específicos dessas pessoas migrantes. Concomitantemente, o reconhecimento formal dessa categoria migratória, seja na legislação doméstica ou internacional, garantiria aplicabilidade imediata de direitos (individuais e coletivos) e obrigações (estatais) na esfera político-normativa.

\section{Do não reconhecimento às formas alternativas de proteção}

Embora os "refugiados ambientais" não sejam reconhecidos como uma categoria de refugiados ou de grupo vulnerável com garantias específicas na proteção internacional da pessoa humana é possível identificar algumas formas por meio das quais governos, organizações internacionais e não governamentais buscam oferecer respaldo a esses migrantes forçados, inclusive sob a perspectiva jurídica. Entre eles, destacam-se os manuais de campo que auxiliam no tratamento dos "refugiados ambientais" e das demais vítimas de desastres ambientais, especialmente naqueles relacionados às mudanças climáticas (Proyecto de Brookings-bern sobre Desplazamiento Interno, 2011; Ocha, 2012; UNISDR, 2012), além do surgimento de áreas técnicas sobre migração motivada por causas ambientais nos organismos internacionais, a exemplo

$\overline{18}$ De acordo com o artigo 33 da Convenção de 1951. 
da Organização Internacional para Migrações (OIM), Alto Comissariado das Nações Unidas para Refugiados (ACNUR) e na estrutura da IFRC.

Importante destacar, ademais, que a literatura internacional sobre Redução do Risco de Desastres (DRR, na sigla em inglês), relacionada não apenas aos efeitos adversos da mudança e variabilidade climáticas, mas também à interferência antrópica danosa ao meio ambiente, tem cada vez mais suscitado o tema dos direitos humanos como objeto a ser protegido nas ações de socorro às vítimas de desastres (Proyecto de Brookings-bern sobre Desplazamiento Interno, 2011).

As projeções, embora díspares a respeito da quantidade de pessoas ambientalmente forçadas pelo mundo, indicam que a maioria dos "refugiados ambientais" são, na verdade, migrantes internos e não migrantes internacionais (IOM, 2009). Embora as normas internas dos Estados - em conjunto com os tratados internacionais por eles internalizados - sejam responsáveis por oferecer respaldo às pessoas que se encontrem dentro dos seus limites territoriais, quer nacionais ou estrangeiros, o direito internacional prevê recursos específicos para os deslocados internos.

Os Princípios Norteadores sobre Deslocamento Interno, de 1998, compõem o documento de soft law ${ }^{19}$ mais importante no que tange ao tema dos deslocados internos (IDPs, na sigla em inglês). O documento define IDPs como sendo:

Pessoas que, em grande número, foram forçadas a deixar seus lares rápida e inesperadamente como resultado de conflito armado, lutas internas, violações sistemáticas de direitos humanos ou de catástrofes naturais ou provocadas pelo homem, e que estão no território do seu próprio país. (Kälin, 1998, p. 1, item 2)

Westra (2009) argumenta que, apesar da grande importância dos princípios norteadores de proteção aos deslocados internos, a proteção jurídica dos "refugiados ambientais", diante da ausência de normativa específica, continua problemática não apenas em virtude das incertezas impostas pelas mudanças climáticas ou da tensão político-migratória internacional, mas, sobretudo, em razão de a proteção dos deslocados internos representar uma tensão entre a soberania estatal e a demanda protetiva dos direitos humanos.

Não resta dúvida de que o desafio normativo em torno dos "refugiados ambientais" está posto, sob o direito interno e o internacional, e aumenta quanto maior a intensidade dos desastres ambientais e das mudanças climáticas. Por isso, é preciso ultrapassar o debate de que "'refugiados ambientais' não são refugiados (convencionais)" para propor soluções concretas e imediatas

${ }_{19}$ Refere-se às normas não vinculantes de direito internacional, a exemplo das Declarações e Resoluções de organismos internacionais. 
com vistas a um efetivo respaldo jurídico dessa categoria de pessoas na ordem internacional.

Nesse sentido, as soluções jurídicas vinculantes (hard law) de alcance internacional para a proteção e o reconhecimento dos "refugiados ambientais" podem ocorrer por meio de:

(i) Estabelecimento de um tratado internacional específico para o reconhecimento e a proteção jurídica dos "refugiados ambientais"; e

(ii) A utilização de normas já em vigor no Direito Internacional para proteger os "refugiados ambientais", a exemplo da proteção complementar do Direito Internacional das Pessoas Refugiadas.

Ambas perspectivas, entretanto, apresentam prós e contras:

a) Enquanto um novo tratado internacional apenas para responder às necessidades específicas dos "refugiados ambientais" seja mais adequado sob a perspectiva da proteção jurídica, as fases comuns a todo tratado internacional (negociação, assinatura e ratificação) tendem a consumir grande lapso temporal, sem contar a produção de eficácia do tratado no caso concreto, que nem sempre é imediata;

b) Normas jurídicas pré-existentes, sobretudo aquelas advindas das três vertentes da proteção internacional da pessoa humana, embora prontas para produzir eficácia, não respondem adequadamente à proteção jurídica dos "refugiados ambientais", que nem sequer são reconhecidos como uma categoria de pessoas na ordem jurídica internacional.

No tocante a uma normativa internacional específica, há três propostas principais em discussão de tratados internacionais para a proteção jurídica dos "refugiados ambientais", a saber:

I) Proposta do governo das Ilhas Maldivas de criar um protocolo específico sobre a proteção jurídica dos "refugiados ambientais" a ser incorporado à Convenção de 51 e ao seu Protocolo de 67 de modo a ampliar os critérios de perseguição e incluir entre eles as mudanças climáticas (Ministry of Environment, Energy and Water, 2006);

II) Projeto de Convenção Relativa ao Estatuto dos Deslocados Ambientais do Centre de Recherche Interdisciplinaire en Droit de L'environnement, de L'aménagement et de L'urbanisme (CRIDEAU) e do Centre de Recherche sur les Droits de la Personne (CRDP), da Universidade de Limonges, que propõe a garantia de direitos aos deslocados ambientais nos planos interno e internacional e seu acolhimento e eventual retorno com base no princípio da solidariedade internacional, da não discriminação, da proteção efetiva e das responsabilidades comuns porém diferenciadas (Prieur, 2014); e

III) Convenção para as Pessoas Deslocadas pelas Mudanças Climáticas (CCDP, na sigla em inglês), liderada pelo professor australiano David Hodgkinson, prevê a aproximação do tema dos "refugiados ambientais" 
com os instrumentos internacionais relativos às mudanças climáticas e propõe o estabelecimento de um organismo internacional que trate de todos os assuntos relacionados aos "refugiados ambientais" (Hodgkinson, Burton, 2009).

Diante da ausência de normas jurídicas específicas e vinculantes de alcance global para a proteção dos "refugiados ambientais", sugerem-se outras possíveis soluções jurídicas que podem ser aplicadas isolada ou concomitantemente:

(i) A legislação doméstica como forma de reconhecer e proteger os "refugiados ambientais" dentro do território estatal ou no exterior, desde que sob a jurisdição do Estado em questão;

(ii) A judicialização do "refúgio ambiental" nos planos interno e internacional como forma de obrigar os Estados a promoverem regularização migratória, ajuda humanitária e outras necessidades prementes relacionadas aos "refugiados ambientais";

(iii) Acordos regionais de proteção e cooperação para o reassentamento (mesmo que temporário) de "refugiados ambientais", sobretudo daqueles vítimas de desastres ambientais.

Como sugestão à solução jurídica para a proteção internacional dos "refugiados ambientais", Kolmannskog e Trebbi afirmam que:

O regime dos direitos humanos, o princípio da não devolução e os mecanismos de proteção complementar podem constituir elementos básicos para criar novas formas de proteção, particularmente em relação ao conceito de retorno: se o retorno não é possível, permissível nem razoável devido às circunstâncias que predominam no local de origem e à situação pessoal, deve-se conceder à pessoa tanto proteção quanto um estatuto claro. A vinculação do retorno com os direitos humanos globais oferece a vantagem de permitir uma interpretação dinâmica, mas também oferece margem para discricionariedade. (2010, p. 408. Tradução livre)

Portanto, diante da atual ausência de um instrumento jurídico específico para assegurar os direitos dos "refugiados ambientais" é importante, por meio da cooperação internacional, da disposição política de governos e organismos internacionais e da atuação dos órgãos judiciais, assegurar ao menos os direitos básicos dos "refugiados ambientais", seja por meio de uma interpretação extensiva de normas internas e internacionais ou mesmo na construção de uma governança migratória-ambiental global que possibilite a utilização de instrumentos, atores e instituições já existentes para a proteção dessas pessoas (Claro, 2015).

\section{Desafios na proteção internacional dos "refugiados ambientais": quais os caminhos viáveis para seu efetivo respaldo jurídico?}

Se o regime dos refugiados é visto como um corretivo para um sistema estatal que falha ao proteger os direitos e as garantias fundamentais desses indivíduos (Betts, 2009b), qual seria, então, o regime propício a garantir que os 
"refugiados ambientais" tenham respeitados esses mesmos direitos e garantias diante de um desastre ambiental que lhes tirou a moradia e as condições de sobrevivência? Parece que a resposta não se encontra apenas no regime geral de DIDH ou mesmo no de DIH, uma vez que as vulnerabilidades e as necessidades específicas dessas pessoas poderiam não ser eficazmente garantidas.

Os "refugiados ambientais" necessitam de proteção jurídica tanto do direito interno estatal, sejam como nacionais ou imigrantes, quanto do Direito Internacional. Se no plano jurídico global as dificuldades começam com o reconhecimento do "refugiado ambiental" como uma categoria de pessoas na ordem jurídica internacional, no direito interno eles ficam à mercê de eventuais restrições à migração e à legislação local que podem limitar seus direitos ou não garantir que eles sejam preservados.

Da mesma forma que os refugiados convencionais, quando são forçados a deixar seu país de origem porque esse Estado não pôde garantir-lhes os direitos humanos e nem evitar seu bem-fundado temor de perseguição, também o "refugiado ambiental", diante de uma situação de extrema gravidade ambiental que impeça sua sobrevivência, precisa de respaldo jurídico adequado, seja dentro do país de origem ou fora dele.

A respeito dos refugiados convencionais, Betts afirma que "assegurar que refugiados recebam acesso à proteção importa tanto para os direitos humanos como para a segurança internacional" (2009b, p. 1), situação que igualmente se aplica à proteção jurídica dos "refugiados ambientais". Alguns autores ${ }^{20}$, inclusive, veem o tema dos "refugiados ambientais" essencialmente como assunto de segurança internacional que demanda e demandará ações por parte de governos e pela comunidade internacional, especialmente quando a migração forçada ocorre entre países em situação de conflito.

Ao mencionar o sentido político internacional da proteção dos refugiados, Betts afirma que:

[...] a existência de proteção também contribui para a estabilidade internacional. Ela assegura que pessoas cujos direitos não podem ser garantidos por seu próprio Estado são, contudo, reintegradas num Estado do sistema internacional. Sem acesso a proteção, aqueles que fogem de perseguição seriam apátridas. Encontrar uma forma de satisfazer suas necessidades evita a possibilidade de que essas pessoas caiam para fora do sistema de Estados e se tornem fonte de instabilidade ou uma ameaça à segurança estatal. (2009b, p. 7. Tradução livre)

Embora o autor tenha-se referido explicitamente aos refugiados convencionais, a justificativa que ele apresenta para a existência da sua proteção internacional também se adequa ao caso não apenas dos "refugiados ambientais", mas aos imigrantes em geral, especialmente aos fluxos de migração

${ }^{20}$ A exemplo de Myers (2005), Matthew et alii (2010), Mazo (2010) e Welzer (2010). 
internacionalmente forçada, na qual ainda se inclui o tráfico de pessoas (Chetail, 2019).

Não obstante eventuais esforços de normatização específica dos direitos dos "refugiados ambientais" ou da adaptação de instrumentos existentes, para que esses direitos sejam aplicados ao caso concreto "é necessária uma imprescindível atividade judicial que concretiza o conteúdo das normas de direitos humanos" (Carvalho Ramos, 2019, p. 25-26), uma vez que essas normas se apresentam como princípios jurídicos e propositalmente são "caracterizadas pela vagueza, abstração e abertura" (Carvalho Ramos, 2019, p. 25) de modo a serem aplicados a uma situação específica.

Nesse sentido, Carvalho Ramos pondera que "a proteção de direitos humanos é antes um exercício de prudência judicial do que labor legislativo" (2019, p. 27). No caso da proteção jurídica dos "refugiados ambientais", faltam não apenas o aspecto normativo, mas também a prática judicial disseminada para melhor delinear as formas de proteção a esses migrantes.

Não apenas a prática judicial é fundamental no respaldo jurídico aos "refugiados ambientais" como também a cooperação internacional é essencial para garantir proteção aos migrantes forçados (Betts, 2009a, p. 2), sejam eles refugiados convencionais ou "refugiados ambientais". A solidariedade internacional baseada na narrativa humanitária, especialmente diante de um desastre natural extremo, também é usualmente entendida como sendo fundamental na assistência imediata ou no longo prazo para as comunidades e países afetados (Mayer, 2016; Cubie, 2014).

Dessa forma, os atores envolvidos com redução do risco de desastres, especialmente aqueles que prestam assistência humanitária in loco para os "refugiados ambientais", desempenham papel imprescindível na garantia de que, na ausência de normativa específica, essas pessoas terão respeitados ao menos partes dos seus direitos garantidos pelos instrumentos internacionais de proteção à pessoa humana.

\section{Considerações Finais}

A mudança e a variabilidade climáticas, além dos desastres ambientais não relacionados a elas, impõem a necessidade de se pensar e efetivar alternativas jurídicas de proteção às pessoas, nelas incluídas os "refugiados ambientais". Esses novos fluxos migratórios forçados demandam adaptações e atualizações do direito para suprir as necessidades específicas dos distintos grupos de migrantes, que não necessariamente teriam todos os seus direitos garantidos pelo regime geral de proteção internacional da pessoa humana nos moldes como hoje se encontra. 
Embora o Direito Internacional atual não contemple a proteção dos "refugiados ambientais" enquanto grupo específico é possível identificar normas de cada uma das três vertentes da proteção internacional da pessoa humana aplicáveis a eles:

a) Do Direito Internacional dos Direitos Humanos, aplicam-se todas as normas gerais e, em particular, o direito de migrar, à habitação, à saúde, à propriedade, entre outros.

b) Do Direito Internacional Humanitário, além de todas as normas aplicáveis aos "refugiados ambientais" que se encontrem em situação de conflito armado interno ou internacional, também os crescentes esforços de assistência humanitária às vítimas de desastres ambientais; e

c) Do Direito Internacional das Pessoas Refugiadas, as normas da Convenção de 51 e do seu Protocolo de 67 quando os "refugiados ambientais" se enquadram em uma das categorias dos refugiados convencionais, além dos princípios e diretrizes de proteção que podem inspirar a elaboração de uma normativa futura e específica para essa categoria de pessoas migrantes.

Como afirma Delmas-Marty, "a universalidade dos direitos do homem remete preferencialmente a um universo mental que a um universo real" (2003, p. 19), não apenas em razão da diversidade de sistemas jurídicos, mas, sobretudo, em virtude do distanciamento entre a pregação e a prática dos direitos humanos, do contexto local ao global. O desafio está, portanto, nas formas de proteção, especialmente dos grupos mais vulneráveis, e na eficácia dos métodos empregados para assegurar que os direitos não sejam desrespeitados.

Nesse sentido, a discussão acerca da proteção jurídica dos "refugiados ambientais", seja por meio de propostas de tratados internacionais específicos ou da utilização da normativa existente, particularmente aquela das três vertentes da proteção internacional da pessoa humana, busca, sobretudo, garantir que o direito internacional contemporâneo esteja apto à proteção de vítimas potenciais de direitos humanos que migram em razão de sérias rupturas ambientais no seu local de origem e que ameaçam a existência desses grupos humanos.

Considerando o aumento dos desastres ambientais no mundo e as estimativas de centenas de milhares de "refugiados ambientais" por todo o planeta, os instrumentos jurídicos precisam estar disponíveis para os tomadores de decisão por meio do estabelecimento de políticas públicas locais ou formas de cooperação e solidariedade internacionais, assim como para juízes de tribunais domésticos e internacionais.

Mesmo que a judicialização do "refúgio ambiental" ainda seja bastante tímida e voltada para o reconhecimento de uma categoria migratória inexistente 
no direito internacional e na maioria das legislações internas, o entendimento do CCPR/ONU, de novembro de 2019, de que as mudanças climáticas violam os direitos humanos e de que o princípio da não devolução deve ser aplicado aos "refugiados ambientais", constitui precedente importante no contexto da lacuna jurídica e dos entraves políticos para garantir o exercício dos direitos humanos dessas pessoas migrantes.

Por isso, buscar uma efetiva proteção no direito interno e internacional para os "refugiados ambientais" é mais relevante e premente do que o discurso de que "'refugiados ambientais' não são refugiados (convencionais)", seja alocando-os em qualquer uma das três vertentes da proteção internacional da pessoa humana, em decisões de órgãos judiciais ou quasi judiciais em casos específicos ou no estabelecimento de uma governança migratória que os acolha efetiva e eficazmente sob as perspectivas política e jurídica internacional.

\section{Referências bibliográficas}

ACCIOLY, Hildebrando; NASCIMENTO E SILVA, G. E. do; CASELLA, Paulo Borba. Manual de Direito Internacional Público. São Paulo: Atlas, 2019.

BARDSLEY, Douglas K.; HUGO, Graeme J. Migration and climate change: examining thresholds of change to guide effective adaptation decision-making. Population and Environment, v. 32, p. 238-262, 2010.

BATTISTELLA, Graziano. Migration and human rights: the uneasy but essential relationship. In: GUCHTENEIRE, Paul de; PÉCOUD, Antoine; CHOLEWINSKI, Ryszard. Migration and Human Rights: the United Nations Convention on Migrat Worker's Rights. Cambridge: Cambridge University Press/ UNESCO, 2009, p. 47-69.

BETTS, Alexander. Forced Migration and Global Politics. Sussex: Wiley-Blackwell, 2009a.

BETTS, Alexander. Protection by Persuasion: international cooperation in the refugee regime. Ithaca: Cornell University Press, 2009b.

BORGES, Leonardo Estrela. O Direito Internacional Humanitário. Belo Horizonte: Del Rey, 2006.

CANÇADO TRINDADE, Antônio Augusto; PEYTRIGNET, Gérard; RUIZ DE SANTIAGO, Jaime. As Três Vertentes da Proteção Internacional dos Direitos da Pessoa Humana: Direitos Humanos, Direito Humanitário, Direito dos Refugiados. San José/ Brasília: CICV/ IIDH, 1996.

CARVAlHO RAMOS, André de. Teoria Geral dos Direitos Humanos na Ordem Internacional. São Paulo: Saraiva, 2019.

CHETAIL, Vincent. International Migration Law. Oxford: Oxford University Press, 2019.

CLARO, Carolina de Abreu Batista. A Proteção dos "Refugiados Ambientais" no Direito Internacional (Tese de Doutorado). Faculdade de Direito da Universidade de São Paulo, sob a orientação da professora Dra Elisabeth de Almeida Meirelles. São Paulo, abril de 2015. Inédita. 
COLEMAN, Nils. Non-refoulement revised. Renewed review of the status of the principle of non-refoulement as customary international law. European Journal of Migration and Law, v. 5, p. 23-68, 2003.

COMPARATO, Fabio Konder. A Afirmação Histórica dos Direitos Humanos. São Paulo: Saraiva, 2019.

CRÉPEAU, François. Non-refoulement as a principle of international law and the role of the judiciary in its implementation. European Court of Human Rights, Strasbourg, Opening of the Judicial Year, 27 January 2017. Disponível em: <https://www.echr.coe.int/Documents/Speech_20170127_Crepeau_JY_ENG. pdf $>$. Acesso em: 06.04.2020.

CUBIE, Dug. Clarifying the Acquis Humanitaire: a transnational legal perspective on the internalization of humanitarian norms. In: CARON, David D.; KELLY, Michael J.; TELESETSKY, Anastasia (eds.). The International Law of Disaster Relief. Cambridge: CUP, 2014, p. 338-360.

DAUVERGNE, Catherine. Making people illegal: what globalization means for migration and Law. Cambridge: Cambridge University Press, 2008.

DELMAS-MARTY, Mireille. Três Desafios para um Direito Mundial. Rio de Janeiro: Lumen Juris, 2003.

EL-HINNAWI, Essam. Environmental Refugees. Nairobi: UNEP, 1985.

ENVIRONMENTAL JUSTICE FOUNDATION - EJF. Beyond borders: our changing climate - its role in conflict and displacement. London: EJF, 2017.

FERNANDES, Jean Marcel. A Promoção da Paz pelo Direito Internacional Humanitário. Porto Alegre: Sergio Antonio Fabris Editor, 2006.

FISCHEL DE ANDRADE, José Henrique. Direito Internacional dos Refugiados: Evolução Histórica (1921-1952). Rio de Janeiro: Renovar, 1996.

GEISLER, Charles; CURRENS, Ben. Impediments to inland resettlement under conditions of accelerated sea level rise. Land Use Policy, v. 66, p. 322-330, 2017.

GEMENNE, François; BRÜKER, Pauline; IONESCO, Dina (Ed.). The State of Environmental Migration 2011. Paris: Institute for Sustainable Development and International Relations (IDDRI) / International Organization for Migration (IOM), 2012.

HODGKINSON, David. BURTON, Tess. Towards a Convention for Persons Displaced by Climate Change. Seminar presentation at the Grantham Research Institute on Climate Change, the London School of Economics, 6 March 2009. Disponível em: $\quad$ <http://www.ccdpconvention.com/documents/DH\%20TB\%20LSE\%20 presentation.pdf $>$. Acesso em: 06.04.2020.

HOMER-DIXON, Thomas F. Environmental scarcities and violent conflict: evidence from cases. International Security, v. 19, n. 1, p. 5-40, Summer 1994.

HUGO, Graeme. Environmental concerns and international migration. The International Migration Review, v. 30, n. 1, Special issue: ethics, migration and global stewardship, p. 105-131, Spring 1996. 
HUGO, Graeme. Climate Change-Induced Mobility and the Existing Migration Regime in Asia and the Pacific. In: McADAM, Jane (ed.). Climate Change and Displacement: multidisciplinary perspectives. Oxford: Hart Publishing, 2010, p. 9-35.

HUMPHREYS, Stephen (ed.). Human Rights and Climate Change. Cambridge: Cambridge University Press, 2010.

INTERNATIONAL FEDERATION OF RED CROSS AND RED CRESCENT SOCIETIES - IFRC. IFRC policy on migration: the 10 migration principles. Geneva: ICRC, $\mathrm{s} / \mathrm{d}$., 4 fls.

INTERNATIONAL ORGANIZATION FOR MIGRATION - IOM. Migration, Environment and Climate Change: assessing the evidence. Geneva: IOM, 2009. JUBILUT, Liliana Lyra; APOLINÁRIO, Silvia Menicucci. A necessidade de proteção internacional no âmbito da migração. Revista Direito GV, São Paulo, n. 11, p. 275-294, jan./jun. 2010.

KÄLIN, Walter. Guiding Principles on Internal Displacement - Annotations. Studies in Transnational Legal Policy n. 38. The American Society of International Law, The Brookings Institution - University of Bern Project on Internal Displacement, Washington, DC, 2008. Disponível em: <https://www.brookings.edu/wpcontent/uploads/2016/06/spring_guiding_principles.pdf>. Acesso em: 17.07.19.

KOLMANNSKOG, Vikram; TREBBI, Lisetta. Cambio climático, desastres naturales y desplazamiento: un enfoque múltiple para resolver las brechas de protección. International Review of the Red Cross, n. 879 (Selección de Artículos 2010), p. 389-409, Septiembre de 2010,.

KRASNER, Stephen D. Structural Causes and Regime Consequences: Regimes as Intervening Variables. International Organization, v. 36, n. 2, International Regimes, p. 185-205, Spring, 1982.

McADAM, Jane (ed.). Climate Change and Displacement: multidisciplinary perspectives. Oxford: Hart Publishing, 2010.

MCLNERNEY-LANKFORD, Siobhán; DARROW, Mac; RAJAMANI, Lavanya. Human Rights and Climate Change: a review of the international legal dimensions. Washington, D.C.: The World Bank, 2011.

MAERTENS, Lucile. Le Haut Commissariat des Nations Unies pour les Réfugiés (HCR) face aux catastrophes naturelles: ce que le tsunami de 2004 a change. Paris: L'Harmattan, 2012.

MÁRMORA, Lelio. Modelos de Gobernabilidad Migratoria: la perspectiva política en América del Sur. Revista Interdisciplinar da Mobilidade Humana, Brasília, ano XVIII, n. 35, p. 71-92, jul./dez. 2010.

MATTHEW, Richard A.; BARNETT, Jon; MCDONALD, Bryan; O'BRIEN, Karen O. (eds.). Global Environmental Change and Human Security. Cambridge: MIT Press, 2010.

MAZO, Jeffrey. Climate Conflict: how global warming threatens security and what to do about it. London: The International Institute for Strategic Studies, 2010.

MAYER, Benoit. The Concept of Climate Migration: advocacy and its prospects. Cheltenham: Edward Elgar, 2016. 
MORETTI, Sebastien; BOZON, Tiziana. Some reflections on the IFCR's approach to migration and displacement. International Review of the Red Cross, n. 99, v. 1, p. 153-178, 2017.

MYERS, Norman. Environmental Refugees: an emergent security issue. $13^{\text {th }}$ OSCE Economic Forum, Prague, 23-27 May 2005. Disponível em: <http://www.osce. org/eea/14851>. Acesso em: 17.07.19.

OFFICE FOR THE COORDINATION OF HUMANITARIAN AFFAIRS - OCHA. OCHA Annual Report 2010. Geneva: UN, 2011.

ORGANIZAÇÃO DAS NAÇÕES UNIDAS. Declaração Universal de Direitos Humanos. Paris, 10 de dezembro de 1948.

PRIEUR, Michel. Quel statut pour les déplacés environnementaux ? In: TOURPICHE, Anne-Marie (ed.). La protection internationale et européenne des réfugiés. La Convention de Genève du 28 juillet 1951 relative ao statut des réfugiés à l'épreuve du temps. Paris: Pedone, 2014, p. 127-156.

Proyeto de Brookings-Bern sobre Desplazamiento Interno. Directrices Operacionales del IASC sobre la Protección de las Personas en Situaciones de Desastres Naturales. Washington, D.C., Mayo de 2011.

REPUBLIC OF THE MALDIVES (MINISTRY OF ENVIRONMENT, ENERGY AND WATER). First Meeting on Protocol on Environmental Refugees: recognition of Environmental Refugees in the 1951 Convention and 1967 Protocol relating to the Status of Refugees. Male, 14-15 August, 2006.

SASSÒLI, Marco; BOUVIER, Antoine. Un droit dans la guerre ? Cas, documents et supports d'enseignement relatifs à la pratique contemporaine du droit international humanitaire. Genève : CICR, v. 1, 2003.

SMITH, Dan; VIVEKANANDA, Janani. A Climate of Conflict: links between climate change, peace and war. London: International Alert, November 2007.

UNITED NATIONS HUMAN RIGHTS COMMITTEE - UNHRC. COMMITTEE ON CIVIL AND POLITICAL RIGHTS - CCPR. Views adopted by the Committee under article 5 (4) of the Optional Protocol, concerning communication No. 2728/2016. Adopted by the Committee at its 127 th session (14 October -8 November 2019). Publication: 7 January 2020.

UNITED NATIONS STRATEGY FOR DISASTER RISK REDUCTION - UNISDR. Disaster Risk Reduction \& Climate Change Adaptation in the Pacific: an institutional and policy analysis. Geneva: UN, 2012.

WELZER, Harald. Guerras Climáticas: por que mataremos e seremos mortos no século 21. São Paulo: Geração Editorial, 2010.

WESTRA, Laura. Environmental Justice \& the Rights of Ecological Refugees. London: Earthscan, 2009. 